\title{
3rd Summer School of the Asian Pacific Society of Hypertension/International Society of Hypertension (Ayutthaya, Thailand 22nd - 26th July)
}

Dean Picone ${ }^{1}$, Rachel Climie ${ }^{1,2}$

\begin{abstract}
${ }^{1}$ Menzies Institute for Medical Research, Hobart, Tasmania, Australia
${ }^{2}$ Baker Heart and Diabetes Institute, Melbourne, Victoria, Australia
\end{abstract}

The 3rd Summer School of the Asian Pacific Society of Hypertension in collaboration with the International Society of Hypertension (ISH) was held in Ayutthaya, Thailand from the 22nd to 26th July 2019. The summer school was successfully organised by Professor Trefor Morgan and the Thai Hypertension Society, where 29 scholars and 10 faculty from 16 countries in the Asia-Pacific region and beyond enjoyed stimulating scientific discussion and wonderful hospitality.

The first requirement of the summer school was a group photo (Figure 1). After this task each summer school scholar presented an abstract within themes including hypertension

epidemiology, prevention or treatment, blood pressure measurement or secondary hypertension. Scholars were also given the opportunity to present

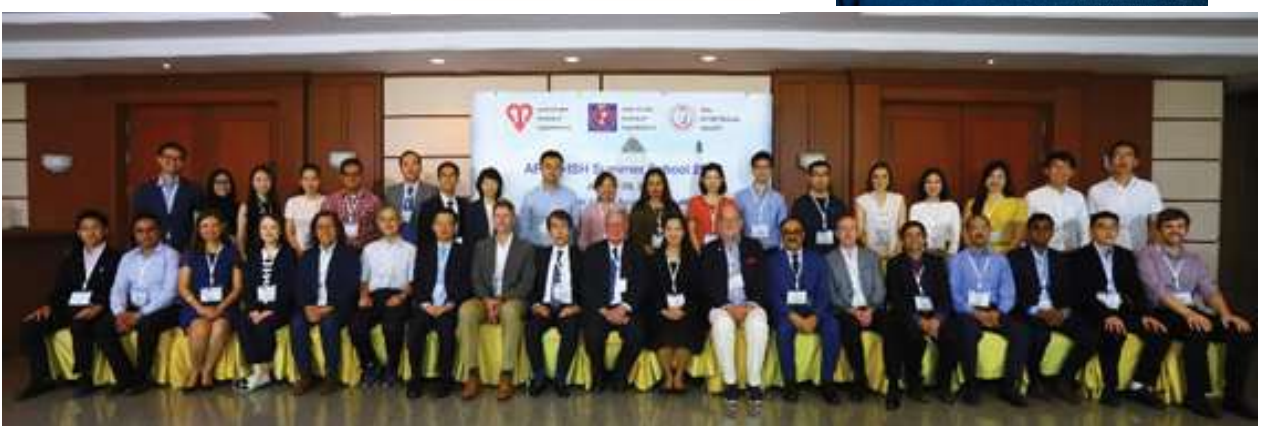

Figure 1. Summer school scholars \& faculty members.

their current research findings which included novel interventions for the treatment of hypertension and blood pressure measurement issues.

Faculty members gave lectures on a variety of topics including the role of the sympathetic nervous system and renin angiotensin system in hypertension, and resistant hypertension and presented fascinating case studies which were a highlight for many scholars.

The summer school scholars and faculty were also treated to an afternoon social activity exploring the historic sights of Ayutthaya -which was Thailand's capital city until 1767. Highlights included the amazing Arts of the Kingdom

Museum (Figure 2) and Wat Mahathat's Buddha Head. Ruan Kruger (ISH-New Investigators Committee lead) represented the ISH on the faculty and he shared interesting insights on paediatric hypertension and promoted the New Investigator Network of the society. Other ISH representatives included Thomas Unger and Markus Schlaich.

Overall, the 3rd Summer School was a great learning and networking experience for all. Indeed, the scholars are already continuing discussions with the aim to establish enduring collaborations. The 4th iteration of the summer school is planned for 2021 and new investigators from the Asian-Pacific region should keep an eye out for future details. All scholars were extremely grateful for the support of their national hypertension societies which provided financial assistance to attend the summer school.

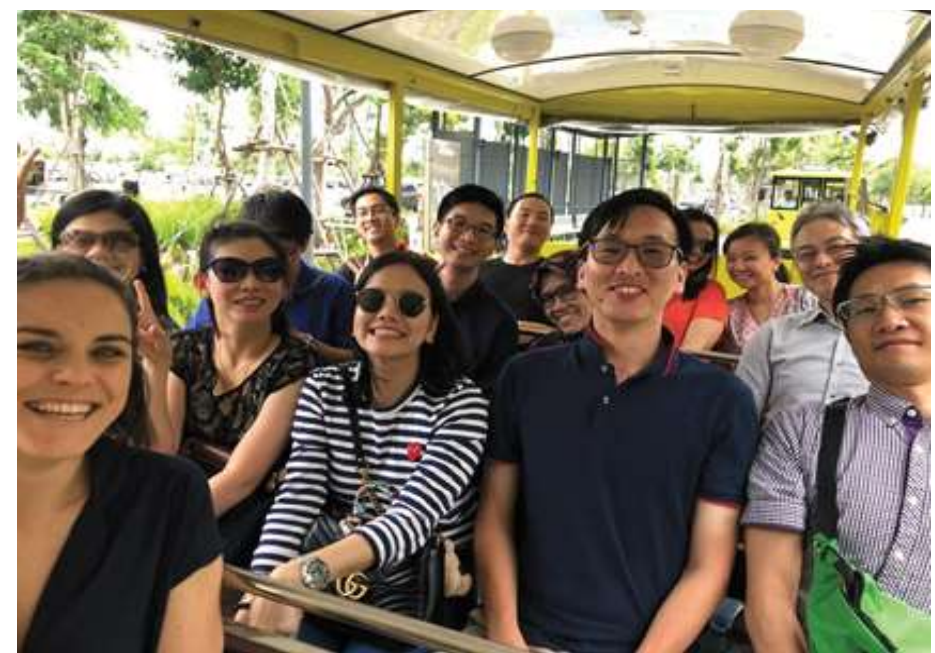

Figure 2. Summer school scholars and faculty on their way to Arts of the Kingdom Museum. 